\title{
Book review: Eco-Immunology: Evolutive Aspects and Future Perspectives*
}

\author{
MOHAMMAD REZA ATASHZAR', RASOUL BAHARLOU ${ }^{1}, M^{\prime} O H A M M A D ~ B O R J I^{2}$, \\ FERYAL DABAGH-GORJANI ${ }^{I}$ \\ ${ }^{1}$ Department of Immunology and Microbiology, School of Medicine, Fasa University of Medical Sciences, Fasa, Iran \\ ${ }^{2}$ Department of Biochemistry, School of Medicine, Shiraz University of Medical Sciences, Shiraz, Iran
}

"Malagoli D, Enzo Ottaviani E (eds.) (2014): Eco-Immunology: Evolutive Aspects and Future Perspectives. Springer, Dordrecht, Heidelberg, New York, London. ISBN 978-94-017-8711-6

\begin{abstract}
This book is a comprehensive book, which has been prepared to help understand the energy interconnection among immune response and ecology, biological systems, physiology, and evolution. This specific book has been written in a unique manner and attempts to provide an "all-round" perspective of eco-immunological concepts by using a simple collection of articles.

The authors have provided an overview of the role of other sciences in immunology. The book is a collection of articles that were written by scientists in departments of life sciences, experimental and diagnostics, immunology, and ecology, collected by Davide Malagoli and Enzo Ottaviani. The topics included in this book are classified into nine chapters.

Its major strength is the complete coverage of eco-immunological concepts. Also, all relevant issues from basic to advanced concepts are explained. Immune systems need energy for function and response. The tight interconnection between energy availability and immune response is one of the main focuses of eco-immunology that is described in this book.
\end{abstract}

Key words: immunology, ecology, review.

(Centr Eur J Immunol 2018; 43 (1): 114-115)

In Chapter 1, "From Immunology to Eco-Immunology More than a New Name", basic structures of eco-immunology and also environmental and antigenic effects on immunology are described as an inseparable part of the dynamic physiology of animals. In this chapter authors discuss feasible lab-research or a test for presentation of challenges between immunology and ecology in the laboratory.

Chapter 2, "System Biology Models and Conceptualizations Applied to Eco-Immunology", is intended to give a comprehensive overview of population dynamics, basic simulation and mathematical models. Also schematic diagrams based on epidemiological dynamics of pathogens and duration of memory are depicted. On the other hand, the chapter also provides how ecological concepts can be useful in the study of different aspects of the immune system.

Chapter 3, "Reproductive and Immune System Interactions in the Context of Life History and Sexual Selection Theory", brings forward trade-offs of reproduction as one of the basic tenets of eco-immunology and the sources of host variation. Authors called this interaction life history. They have recommended the role of parasites in shaping reproductive adaptations through sexual selection theory for studying the host's response to infections. Two novel methods, the genetic model and direct benefit model are presented for this theory.

The main idea of chapter 4, "Host-Parasite Interactions", is that parasites provide a physiological context for immunological response and whether the immune function is dependent on intracellular and extracellular parasite interplay or not. The interesting part of this chapter is about what is lacking and what can be gained in the introduction of parasites and eco-immunology.

Chapter 5 named "Immune-Neuroendocrine Integration and Its Evolution" analyzes interactions between the immune and neuroendocrine systems. The differences between jawed vertebrates and other animals are presented based on lymphocyte cells. These interactions are under the lens of eco-immunology. The existence of memory in

Correspondence: Mohammad Reza Atashzar, Department of Immunology and Microbiology, School of Medicine, Fasa University of Medical Sciences, Fasa, Iran, e-mail: mr.atashzar@yahoo.com Submitted: 26.03.2016; Accepted: 12.05.2016 
the invertebrate immune system is another topic discussed in this chapter.

At the beginning of Chapter 6, "Thymic Maturation and Programmed Cell Death", authors discuss the thymus formation and development. Also they try to introduce thymus as a great source of energy for immune system formation at childhood, so that the immune system would have a successful function in adulthood. T-cell differentiation and maturation is the most important part of the immune system. The thymus has a significant role in the advancement and maintenance of T-cells. Immunosenescence and cell death are also discussed.

In Chapter 7, "The New Antigenic Ecospace of the Globalized World and its Impact on the Immune System: The Battleground of Trade-off and Antagonistic", authors have expressed some aspects of basic, environment and geographical antigen exposure and antigen presentation. This is called "Antigenic Ecospace". This chapter discusses the connection among gut microbiota, normal flora, aging, nutrition and antagonistic pleiotropy. At the end readers can find the association of developed countries with mTOR and $\mathrm{NF}-\kappa \mathrm{B}$ pathways.

Chapter 8, "Population Immunology: Germs, Aging and Inflammation" discusses the alternative between immuno-senescence and low-grade inflammation (inflammaging) versus healthy aging. Antigenic stress via both dietary antigens and hygiene hypothesis are also epigenetic determinants of immunosenescence. Inflammaging in different populations is another topic in this chapter.

The last chapter, "Mouse Models as Paradigms of $\mathrm{Hu}$ man Diseases" focuses on a mathematical model of a mouse and human evolutionary theory called directionality theory. This chapter argues that mice can be reliable models for the early-onset diseases, but they are unsuitable for late-onset inflammatory diseases. Therefore mice will not be effective models for drug design for late-onset stages.

As conclusion remarks, the major strength of this book is the fact that it is a quick reference and provides helpful and continuous mathematical models, immunological competences and evolutionary theories. As the authors said, the most useful aspect of this book is the introduction of eco-immunology as a self-standing field that can be useful for solving hard problems in welfare politics and therapeutic strategies. Generally, this book serves as an available reference for those who wish to find essential knowledge regarding eco-immunology. 